\title{
Acesso à informação pública e democracia: alguns apontamentos
}

\author{
Thiago Gomes Eirão \\ Fernando César Lima Leite \\ Universidade de Brasília - UNB, Brasil
}

REVIEW

\begin{abstract}
Resumo
Objetivo. Trata da temática do acesso à informação pública a partir de uma análise frente ao seu relacionamento com a democracia.

Método. A partir do diálogo com a literatura sobre o acesso à informação pública, são apresentados pontos norteadores para o debate sobre o processo de amadurecimento do regime democrático e consequentemente da sociedade centrada na importância da disponibilização da informação pública de maneira livre e tendo o sigilo uma exceção. Aborda também a importância do surgimento de normativos legais, conhecidos como leis de acesso à informação, na construção de condições que garantam o direito à informação pública.

Resultados. Os resultados demonstraram que o engajamento civil na vida dos agentes públicos, aliado às tecnologias de informação que cada vez mais impedem ações escusas do Estado, conduziram à construção de um ambiente onde o acesso à informação e o direito de informar e ser informado ganham forças e começam a ditar o funcionamento das instituições públicas. Surge daí o direito à informação, uma instância poderosa que encontra sustentação a partir de diplomas legais específicos conhecidos como leis de acesso à informação para atuar como um ramo dedicado a estudar e prevalecer ante a cultura de ocultação dos agentes públicos há muito tempo existente.
\end{abstract}

\section{Palavras-chave}

Acesso à informação; Democracia; Informação pública.

\section{Access to public information and the democracy: some thoughts}

\begin{abstract}
Objective. Addresses the issue of information public access based on an analysis of its relationship with democracy. Method. From the dialogue with the literature on access to public information, points are presented for the debate about the maturation process of the democratic regime and, consequently, of the society centered on the importance of making public information available in a free way and keeping secrecy an exception. It also addresses the importance of the emergence of legal norms, known as access to public information laws, in the construction of conditions that guarantee the right to public information.

Results. The results showed that civil engagement in the lives of public agents, together with the information technologies that increasingly prevent the State from doing so, have led to the construction of an environment where access to public information and the right to inform and be informed gain strength and begin to dictate the functioning of public institutions. From this comes the right to information, a powerful instance that finds support from specific legal instruments known as access to information laws to act as a branch dedicated to studying and prevailing before the long-standing culture of public agents.
\end{abstract}

Keywords

Democracy; Information access; Public information. 


\section{Introdução}

Informação é aquele item responsável por transmitir uma ideia que confere significado e sentido, constituindo-se uma condição para a existência e sobrevivência do indivíduo (SHERA, 1977). Estado é o agente responsável por zelar pelo bem-estar social e conduzir a sociedade, por meio de políticas, ao longo do tempo. Política é resultado de um embate de ideias e convicções em torno da garantia do poder de decisão e da condução das ações de um Estado. De acordo com Bobbio; Matteucci e Pasquino (1995), o conceito de política é algo que necessariamente toca na ideia de poder, que, segundo Higino; Araújo e Scott (2008), relaciona-se diretamente a uma situação impositiva, que depende de meios para se efetivar.

Os poderes econômico, político, ideológico e tantos outros são os meios disponíveis para que o Estado conduza a sociedade que o forma. O uso da informação, enquanto instrumento da política, faz-se em um ambiente de choque entre correntes ideológicas diferentes em busca da afirmação de preceitos que os lados julgam serem os corretos para a sociedade. Palco natural e propício para esse embate, a democracia tem se deparado com vários desafios para se constituir enquanto forma de governo ao longo dos anos.

Democracia, que deriva da junção das palavras gregas demos (povo) e kratos (poder) e possui várias acepções, pode ser entendida como uma forma de governo que se baseia em três princípios: soberania popular, distribuição equitativa de poder e designação de direitos e deveres para todos dentro da sociedade. Em outras palavras, de acordo com Tocqueville (2010, p. 51), "a democracia constitui o estado social, a lei das leis que determina o direito político".

Nascido na Grécia antiga, o conceito de democracia percorreu um longo caminho até que, nos tempos modernos, firmou-se como um regime político a ser adotado pelas nações "mesmo com sua ambiguidade geradora de esperanças e de ameaças" (GOYARD-FABRE, 2003, p. 58). Transformada em uma força responsável por legitimar governos e produzir um sistema de pesos e contrapesos com a finalidade de trazer equilíbrio entre as forças presentes na sociedade, evitando a soberania de uma ideia individual em detrimento da coletiva, a democracia se organiza em torno de um sistema representativo (BRAY; SLAUGHTER, 2015) baseado na alternância do poder por meio de eleições e na institucionalização das relações através de políticas asseguradoras de direitos.

Entendidos como parceiros, democracia e direito se entrelaçam com o intuito de produzir relações por meio de políticas igualitárias, cristalinas e de aplicação comum. Pode-se citar como um exemplo a política de informação, que se debruça sobre questões acerca da circulação, divulgação e influência da informação no bem-estar social, na manutenção da democracia e na manutenção do direito universal à informação (FONSECA, 1999).

\footnotetext{
Designando bem menos um regime político que um modelo de sociedade que corresponde a um tipo de mentalidade, ela [democracia] se situa, em sua própria essência e desde sempre, sob o signo da ambivalência. Rica em esperanças, a democracia é para o homem uma promoção política: em sua marcha lenta, ela demarcou a conquista da liberdade dos povos e tornou possível o reconhecimento dos direitos do homem. (GOYARD-FABRE, 2003, p.1).
}

Falar de política e de informação é tratar, dentre outros aspectos, do direito à informação, ideia amplamente preconizada desde o século XX com a consolidação maior dos regimes de governo centrados na democracia e na construção dos ideais de Estados democráticos de direito. A esse respeito, Bento (2015) considera que:

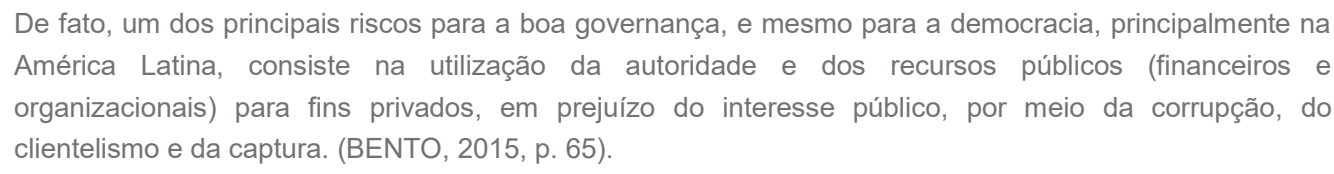

De acordo com a teoria clássica do direito, liberdade de informação e direito à informação possuem algumas diferenças. A primeira, de caráter individual e nem sempre contemplada nas leis, e a segunda, de caráter coletivo, que encontra abrigo em documentos legais (ROTHBERG; NAPOLITANO; RESENDE, 2013), relacionam-se profundamente com a ideia de um fluxo de informação livre, tanto na manifestação quanto na obtenção de qualquer informação. Sendo assim, é possível definir o direito à informação como o "coração da democracia" (CYRANEK et al., 2009, p. 2). 
Aprofundando a discussão em torno dessa questão, Villanueva (2006, p. 10, tradução nossa) argumenta que o direito à informação representa um amadurecimento da sociedade quanto ao livre fluxo de informação definido como um direito, já que "[...] nasceu ante a necessidade de regulamentar e organizar o exercício de um direito natural do homem, reconhecido com essas características nas leis fundamentais de diversos países [...]".

Segundo Khan (2009), o livre fluxo de informações e ideias são conceitos naturalmente associados à democracia, e esses conceitos são centrais para o direito e acesso à informação. De acordo com Mendel (2009, p. 3), "a importância do direito à informação ou do direito a saber é um tema cada vez mais constante no discurso dos especialistas em desenvolvimento, da sociedade civil, dos acadêmicos, da mídia e até dos governos. Que direito é este?". Exatamente na definição do direito à informação é que se concentram os estudos recentes.

Consagrado no artigo 19 da Declaração Universal dos Direitos Humanos (1949), o direito à informação, embora, segundo Melo e Sathler (2005, p. 7), "ainda sob o impacto do pavor", já que se tratava de um período posterior à Segunda Guerra Mundial, é uma das obrigações que os governos têm para que seja possível a promoção e a proteção dos direitos humanos e as liberdades de grupos ou indivíduos, e esse é um direito já reconhecido universalmente pelos sistemas regionais de direitos humanos, tais como: a Organização dos Estados Americanos, o Conselho da Europa e a União Africana.

\footnotetext{
A liberdade de informação e os correlatos direitos à informação e de acesso à informação, além de direitos humanos e fundamentais de alta relevância, representam técnicas democráticas de alta densidade na conformação das relações humanas numa determinada comunidade política e social. Na atualidade, é possível reunir tais direitos e os deveres que thes são inerentes numa disciplina jurídica que acabou por ser denominada Direito da Informação. (SARLET; MOLINARO, 2016, p.11)
}

Circunscrito nos ideais de bem-estar econômico e social das sociedades (ROWLANDS, 1996), o direito à informação constitui o ponto norteador para a construção de políticas públicas de informação voltadas para o ato de fomentar o acesso e a disponibilidade das ações do Estado. Informação pública pode ser entendida como aquele conjunto de documentos/informação gerados ou custodiados pela entidade pública, os quais dizem respeito à atividade governamental. Além disso, significa prestar contas de como o bem público é gerido, não importando o seu suporte, seja ele "impresso, ótico, eletrônico, físico, químico, biológico ou qualquer outro formato que forem criados" (EQUADOR, 2003). De maneira mais ampla, Batista $(2015$, p. 60$)$ a define como:

\footnotetext{
Assim, informação pública, além de ser a informação produzida pelo Estado, é a informação sobre o Estado, a qual também é de interesse público. Nesse sentido, as informações que organizações não governamentais divulgam sobre o funcionamento do Estado também são públicas, no sentido de interesse público, embora não sejam estatais. Nesse aspecto, o conceito de informação pública descrito acima envolve não apenas a informação produzida pelo Estado (informação estatal), mas também aquela que se refere a ele e a que é mantida por ele e gera direito de acesso à sociedade. Desse modo, informação estatal é uma categoria de informação pública. (BATISTA, 2015, p. 60).
}

Partindo de tais premissas, o presente trabalho pretende discorrer sobre alguns pontos que descrevem o relacionamento entre a informação, enquanto um direito, e a consolidação dos Estados democráticos. Diante de tamanha complexidade e possibilidades de análise, este artigo tem como intuito propor uma reflexão sobre os instrumentos que possibilitaram a criação do espaço no qual se insere atualmente a temática do acesso à informação pública.

\section{Democracia, direito e acesso à informação}

O ato de comunicar é inerente à condição humana. Mesmo de maneira não proposital, os indivíduos estão transmitindo mensagens e informações entre si como parte de um contrato social firmado nas bases da formação da sociedade. Comunicação e informação são conceitos que não caminham separados. 
Comunicação é um ato moral e um ato de relacionamento interpessoal, bem como um ato político e um ato de construção social. Comunicação e padrões de coexistência são dois caminhos fundamentais, essenciais e relacionados, pelos quais as pessoas se unem no relacionamento humano. (PASQUALI, 2005, p. 22).

Seja por meio da fala e de gestos seja por um simples posicionamento corporal, as pessoas estão transmitindo sinais que serão interpretados e registrados de diferentes maneiras. Exatamente centrada no registro de informação, aqui entendida como o conjunto de códigos e símbolos que unidos são capazes de encapsular uma ideia que será entendida e produzirá um efeito em outro indivíduo, é que a sociedade humana se desenvolveu ao longo dos séculos, utilizando várias formas com o intuito de permitir a passagem de informação para as futuras gerações. Segundo Higounet (2003, p. 9), “[...] a escrita é mais que um instrumento. Mesmo emudecendo a palavra, ela não apenas a guarda, ela realiza o pensamento que até então permanece em estado de possibilidade".

Ao longo da história, nenhum instrumento foi tão eficaz quanto a escrita no ato de registrar a informação. O ato de escrever por meio de símbolos gráficos conhecidos como letras, sílabas e palavras é o marco da civilização. Para Higounet (2003, p. 10), "a escrita faz de tal modo parte de nossa civilização que poderia servir de definição dela própria. A história da humanidade se divide em duas imensas eras: antes e a partir da escrita".

Foi o registro dos pensamentos que catalisou o surgimento do conceito de direito à liberdade dentro da sociedade e na constituição dos Estados. Sobre o aspecto do registro, o livro, por muitos séculos, apresentou-se como o principal e legítimo instrumento de propagação da escrita, guardião da liberdade e transmissor do conhecimento (DARNTON, 2010). Tal posição de destaque fez com que o livro tivesse em sua história uma relação de amor e ódio com os poderes governamentais no mundo, sejam eles democracias ou ditaduras.

De acordo com Dupuis (1968), a palavra "liberdade" é historicamente a mais citada no direito junto com a palavra "amor". De acordo com Braud (1968, p. 2), "A liberdade é também a inspiração profunda que confere significação permanente, estabilidade às instituições". Liberdade em um conceito mais amplo pode ser entendida como o ato de conferir poder aos indivíduos para que exerçam sua individualidade e possam ser aquilo que desejam ser dentro da sociedade, expressando suas opiniões de maneira livre e espontânea. Decorrente dessa ideia, surge a liberdade de expressão, definida como um direito humano, que consagra a possibilidade de todas as pessoas conhecerem e exprimirem suas opiniões e pontos de vista (ALFONZO, 2004).

\footnotetext{
O direito à liberdade de expressão é considerado pela comunidade internacional como um direito primário e base fundamental de todos os direitos humanos. Dessa forma, a primeira manifestação da vida é a expressão do pensamento, que tem sido o grande construtor das ideologias e sistemas políticos das democracias representativas. (FUENMAYOR ESPINA, 2004, p. 11, tradução nossa).
}

Já sobre o estudo da democracia, levando-se em conta aspectos temporais e espaciais, o exercício é complexo (GUIMARÃES, 2013) tanto pela análise sociológica quanto pelo aspecto legal. Aristóteles (2009) lançou o primeiro apontamento sobre democracia ao afirmar que a liberdade não é o único fundamento dessa forma de governo. Montesquieu (2010, p. 19) trouxe outro fundamento ao afirmar que "[...] o povo em seu conjunto possui o poder soberano, trata-se de uma democracia".

Miranda (1979, p. 136) faz uma análise mais profunda ao defini-la como "[...] a participação do povo na ordem estatal: na escolha dos chefes, na escolha dos legisladores [...]". Já Silva (2003) vai além e afirma que democracia é aquilo que possibilita a concretização dos valores e a convivência humana com base principalmente nos direitos fundamentais do indivíduo.

Baseada no fortalecimento do direito coletivo, da representatividade popular e da forma de governo "do público para o público" (BOBBIO, 2009, p. 84), a democracia, segundo Guimarães (2013, p. 109), "[...] está ligada à evolução histórica da humanidade". Cultuada como o regime de governo ideal e resultante da experimentação ao longo dos séculos pela sociedade (DIAS, 2013), a democracia tem em sua história uma relação intrigante com os Estados, principalmente no contexto latino-americano. Formada por um grupo de 20 países (BETHELL, 2009), a América Latina guarda consigo um histórico conturbado com esse regime. 
Embora ainda se registrem alguns regimes autoritários e totalitários (SILVA, 2014) no século XX, este pode ser compreendido como o século que marcou definitivamente a ruptura da barreira que separava a existência do Estado e da sociedade, principalmente por esta última ter entrado num movimento de consciência do seu papel em uma democracia, por isso surgiram convenções e pactos no contexto latino-americano em torno da necessidade de acesso às informações públicas do Estado. Embora Sorj (2010, p. 10) afirme que a sociedade civil é heterogênea e que, dentro dela, "alojam-se as mais variadas organizações, tipos de atividades, formas de financiamento e tendências ideológicas", é possível identificar uma agenda comum em torno da liberdade à informação pública.

Desde a época da luta contra as ditaduras - quando surgiu na América Latina e tornou-se símbolo e trincheira da luta democrática - até o momento atual, o lugar e o papel da sociedade civil mudaram profundamente. Ainda que ela nunca tenha sido homogênea ou totalmente virtuosa, no contexto político de sua época heroica, foi vista desta forma (SORJ, 2010, p. 7).

Ainda que a realidade moderna possa aparentar um momento extremamente propício à liberdade e às ideias democráticas, Guimarães (2013) e Heinen (2014, p. 13) alertam que a "democracia deve ser construída porque ela não está pronta [...] Sem democracia a informação pública torna-se uma mera aparência”. Corroborando essa ideia de que a concepção da democracia é algo constante, Gurovitz (2017) alerta para os estudos de três rankings que medem a democracia no mundo (Economist Intelligence Unit, Freedom House e Polity Project), os quais demonstram um recuo da democracia na última década, apesar do amplo espaço de interação, comunicação e liberdade criado com a Internet.

Pode-se apontar como principal sintoma dessa mudança o crescimento do engajamento civil, especialmente com o fortalecimento da figura do chamado Terceiro Setor. Segundo Berger (2009), o engajamento civil é um traço característico de democracias em desenvolvimento, que envolve politicamente, socialmente e moralmente os indivíduos da sociedade nas esferas de decisões públicas e privadas, por meio das entidades representativas do Terceiro Setor. Para Perondi (2007, p. 13), ao se falar de Terceiro Setor, fala-se de:

[...] entidades sem fins lucrativos, as organizações difusoras da cultura do voluntariado, as organizações não-governamentais (ONGs) [...] situadas no conjunto do assim chamado Terceiro Setor e os partidos políticos envolvem uma combinação de elementos políticos, ideológicos, econômicos e sociais. (PERONDI, 2007, p. 13).

De maneira simples, Salamon (1998) definiram que organizações desse setor são aquelas que conferem assistência ou serviço à sociedade, tendo como características a estruturação, a autogovernabilidade e o envolvimento de indivíduos através do voluntariado. Tais organizações surgiram a partir da divisão dos setores da atividade humana em três: setor primário (representado pelo mercado), setor secundário (o Estado) e o terceiro com características oriundas dos dois anteriores.

Coelho (2000) afirma que o termo Terceiro Setor surgiu na década de $1970 \mathrm{com}$ pesquisadores nos Estados Unidos e que, a partir da década de 1980, passou a ser usado por pesquisadores europeus. Dessa forma, a autora afirma ainda que aa discussões acerca do tema e das múltiplas denominações para o grupo específico que compõe esse setor são relativamente antigas e que "[...] apenas há pouco tempo ganharam visibilidade junto à opinião pública" (COELHO, 2000, p. 17).

Regules (2006) ressalta que a criação e o funcionamento das organizações desse setor decorrem da autonomia de vontade, satisfação das necessidades de grupos sociais ou da coletividade. Franco (1997) reforça essa ideia de necessidades específicas de grupos sociais, ao alertar que se deve tomar cuidado ao se definirem as ONGs apenas como entidades voltadas para o pensamento público, já que, segundo o autor, existem entidades pertencentes ao Terceiro Setor que não possuem fins públicos, mas sim fins coletivos privados, "[...] que não tem pretensão ou a obrigação de atender a um interesse comum da sociedade e, portanto, que não estão voltadas para o bem comum ou para a chamada utilidade pública" (FRANCO, 1997, p. 59). 
Nos Estados Unidos, a relação entre os órgãos governamentais e o Terceiro Setor é tradicional e está baseada em práticas culturais relacionadas ao associativismo. No Brasil, esse relacionamento vem sendo construído, embora de forma não tão visível e nem tão consistente. (COELHO, 2000, p. 149).

De acordo com Sorj (2010, p. 11): "Dentro das ONGs, podemos distinguir dois tipos ideais no que se refere aos seus focos de atividade: as que se dedicam a influenciar a opinião pública pela promoção de valores e políticas públicas, e as de intervenção social".

$\mathrm{Na}$ sociedade civil coexistem sindicatos de assalariados, organizações indígenas, de camponeses, de empresários, de vizinhos, de mulheres de redes sociais, movimentos sociais e culturais, grupos de opinião, de pressão, instituições cívicas, religiosas, de ação para o desenvolvimento regional ou local. (ÉROSTEGUI, 2009, p. 220)

Foi o engajamento crescente de pessoas e entidades, principalmente das ONGs no cotidiano do Estado, que permitiram o crescimento do movimento de transparência das contas públicas e do conceito de accountability. $O$ crescimento em número e em expressão de organizações privadas, sem finalidade lucrativa e com interesse no bem público, criou um fenômeno chamado "revolução associativa global" (SALAMON, 1998, p. 5).

Tal revolução, segundo Pinto (2001, p. 44), "[...] pode significar uma alteração substantiva na relação entre os cidadãos e o Estado, com interessantes desdobramentos políticos, ao sugerir o surgimento de uma sociedade mais participativa no debate e a definição de seu próprio destino". Experiências como Transparência Brasil , Observatório Social do Brasil e National Council of Nonprofits são apenas algumas das ações que representam essa revolução em busca de instrumentos que permitam a democracia participativa e o acesso à informação pública, com o intuito de contribuir para a transparência da gestão pública e para o combate à corrupção e à prática da cultura do segredo.

Todo esse conjunto de ações levou a uma modificação do Estado informacional (PINHEIRO, 2014) e do chamado regime de informação, que, segundo Braman (2004), representa um conjunto de princípios, sejam eles explícitos ou implícitos, regras, normas e outros procedimentos que permitem a convergência de expectativas e ações dos vários atores envolvidos no ambiente político-informacional. Para Frohmann (1995), os regimes de informação são os impulsionadores das políticas de informação, que são os instrumentos capazes de materializar esses regimes.

\footnotetext{
"Regime de informação" seria o modo de produção informacional dominante em uma formação social, o qual define quem são os sujeitos, as organizações, as regras e as autoridades informacionais e quais os meios e recursos preferenciais de informação, os padrões de excelência e os modelos de sua organização, interação e distribuição, vigentes em certo tempo, lugar e circunstância, conforme certas possibilidades culturais e certas relações de poder. (GONZÁLEZ DE GÓMEZ, 2003, p.61)
}

Na tentativa de convergência de regimes de informação e políticas, o próprio Estado moldou-se a uma nova realidade: deixa de ser burocrático e torna-se Estado informacional ou Estado digital (PINHEIRO, 2014), ou seja, passa a ter a transparência e a participação da sociedade como preceitos e, concomitantemente, incentivam a atividade fiscalizadora dos cidadãos em relação às ações da esfera pública.

Essa mudança do regime de informação impôs um cenário novo no relacionamento dos setores governamentais com os cidadãos, principalmente por intermédio das iniciativas denominadas E-gov ou governo eletrônico, que representaram grandes avanços para o estabelecimento de parâmetros mais equilibrados de disponibilização e acesso às informações de interesse público via Internet (SILVA et al., 2012, p. 4).

Fruto da mudança do regime de informação, as políticas de informação tornam-se cada vez mais pujantes no discurso do Estado, embora sejam pouco percebidas pela sociedade (PINHEIRO, 2014), através da consolidação dos diplomas legais sobre o acesso à informação pública, conhecidos como leis de acesso à informação. Para Pires Júnior (2014, p. 13), "não há que se reconhecer a democracia em ambiente onde o cidadão não é capaz de acessar a informação que se encontra sob a guarda do estado, e consequentemente, onde o agente público não presta conta do exercício da sua função".

Embora não seja algo novo dentro do ordenamento jurídico, já que a primeira lei desse tipo foi criada em 1766 na Suécia (CONTROLADORIA-GERAL DA UNIÃO, 2011), foi especialmente no século XX que Estados do 
mundo inteiro começaram a legislar sobre o tema de forma mais expressiva e clara. Apesar de criadas em tempos e a partir de realidades diferentes, as leis de acesso à informação são diplomas legais que apresentam um tronco comum que organiza as ideais em torno da constituição do direito de acesso à informação. De maneira resumida, é possível organizá-las a partir de 10 ideias condutoras:

1. Toda informação é acessível;

2. O acesso a informação atinge não apenas os órgãos públicos, mas sim entes privados com recursos públicos;

3. Toda informação é objeto do direito de acesso a informação;

4. É obrigação dos órgãos públicos difundirem informação sobre suas funções e atividades;

5. O requerimento de informação deve ter regras claras, justas, não discriminatórias e simples;

6. A lei deve estabelecer as exceções do direito de acesso à informação;

7. A negativa de acesso à informação deve ser acompanhada de uma justificativa elaborada pelo órgão público que prove o motivo;

8. O direito de recorrer a negativa ou obstrução de acesso à informação é um direito disponível a todos;

9. Os agentes públicos estão sujeitos às sanções quando intencionalmente negarem ou obstruírem o acesso à informação.

10. Devem ser adotadas medidas de promoção e implementação do direito de acesso à informação.

Como pode ser observado, o direito de acesso à informação não se prende apenas na questão de criação de direitos, mas também atua fortemente na definição dos deferes inerentes ao Estado e seus agentes para a sua concretização. Tendo a informação como foco e o agente público como o intermediador dessa relação, o ato de fornecer acesso à informação aos indivíduos e à sociedade passar ser uma ação típica de um Estado democrático.

Para Heinen (2014), o acesso à informação é um direito fundamental e configura-se como uma prática claramente democrática, e, sem ela, não existe um poder praticado de forma justa e temperada, sendo a participação popular uma exigência da democracia moderna.

\footnotetext{
Esse diploma normativo, assim, eleva a transparência a um patamar jamais alcançado, formatando, realçando, assim, o próprio princípio da publicidade [...] anseia compor a preservação concomitante da autonomia provas e pública, associando republicanismo e democracia, em uma ação democrática e diálogos, que pressupõe um amplo acesso à informação, em uma compressão qualitativa e quantitativa dos dados públicos. (HEINEN, 2014, p. 13).
}

Diante do exposto e partindo da premissa que a informação é um item que não existe sozinha no espaço, que sua natureza de relacionamento com a realidade da sociedade ocorre de múltiplas formas e intensidade, não há de se falar em democracia como algo desassociado de um ambiente colaborativo e de livre circulação de informações, acessíveis e disponíveis para todos indivíduos. Sendo assim, o acesso à informação é um dos traços característicos do regime democrático que por sua vez, alimenta-se desse instituto para se fortalecer e perdurar. 


\section{Considerações finais}

Fruto da luta de várias gerações e indivíduos, a democracia e seus preceitos de igualdade entre os indivíduos, liberdade de expressão, garantia dos direitos individuais e coletivos e da soberania do povo, formam especialmente nos tempos atuais os pilares que sustentam toda a organização das sociedades modernas e, consequentemente, o instituto da informação enquanto um direito. Desde os tempos primórdios, a informação existe no cotidiano da sociedade, no entanto, ela nunca foi tão presente o na relação do Estado com os indivíduos.

O engajamento civil na vida dos agentes públicos, aliado às tecnologias de informação que cada vez mais impedem ações escusas do Estado, conduziram à construção de um ambiente onde o acesso à informação e o direito de informar e ser informado ganham forças e começam a ditar o funcionamento das instituições públicas. Surge daí o direito à informação, uma instância poderosa que encontra sustentação a partir de diplomas legais específicos conhecidos como leis de acesso à informação para atuar como um ramo dedicado a estudar e prevalecer ante a cultura de ocultação dos agentes públicos há muito tempo existente.

O direito ao acesso à informação debatido amplamente por várias áreas do conhecimento e de múltiplas maneiras, encontra acolhida na Ciência da informação, uma ciência relativamente jovem, mas que já demonstra alguma maturidade frente às questões sobre o processo de produção, organização e transferência da informação, itens cruciais que envolvem o fenômeno da informação mundial. Imensa em quantidade e abrangência, no contexto moderno, a informação adquiriu caráter decisório e vital para a sobrevivência das instituições e das nações, sendo assim, um ativo precioso, penoso e algumas vezes perigoso.

Precioso por ser elevado muitas vezes como o item mais importante para o funcionamento das instituições políticas e econômicas de um país, núcleo sustentador das nações durante vários anos. Por outro lado, um ativo penoso por ser de difícil constituição, que demanda tempo e capacidade para ser organizado e transformado em algo gerador de ganhos. Por fim, um ativo perigoso, já que se usado de maneira errada pode gerar resultados não esperados e negativos tanto para aqueles que o detém como aqueles para o qual ele se destinava.

O acesso à informação, mesmo nos tempos modernos, é ameaçado de diversas formas mesmo naqueles Estados que possuem a democracia como sistema político predominante. Seja em democracias antigas ou ainda aquelas muito jovens, o direito ao acesso à informação é algo que deve ser cultivado, protegido e ensinado de geração para geração não apenas como algo fictício, mas sim como um instrumento real, capaz de transformar a vida de todos dentro de uma sociedade. De maneira análoga, a democracia alimenta-se dessas ideias para se constituir enquanto uma forma de organização da sociedade e ao mesmo tempo, uma maneira mais justa de conduzir a relação entre os indivíduos.

Principal representante dos tempos da racionalidade humana, a democracia é o item que propiciou o surgimento de conceitos preciosos referentes à existência da informação enquanto um patrimônio da sociedade. Informação como direito e acessível para todos não existiria sem a existência do regime democrático como pilar de sustentação das sociedades ou seria debatido com tamanha pujança como assiste-se nos tempos atuais. Informação e democracia ambas ideias se auxiliam mutuamente e equilibram o jogo de forças existentes nas sociedades, que por diversas vezes ainda se encontram assombradas por movimentos autoritários e contrários à filosofia da informação pública como direito do indivíduo.

\section{Referências}

ALFONZO, Alejandro. El avance de un necesario debate: transparencia y libre acceso a la información pública. In: FUENMAYOR ESPINA, Alejandro. El derecho de acceso de los ciudadanos a la información pública: Análisis jurídico y recomendaciones para una propuesta de ley modelo sobre el derecho de acceso de los ciudadanos a la información pública. San José: Unesco, 2004. p. 1-7.

ARISTÓTELES. Política: texto integral. 5. ed. São Paulo: Martin Claret, 2009. 283 p.

BENTO, Leonardo Valles. Acesso a informações públicas: princípios internacionais e o Direito brasileiro. Curitiba: Juruá, 2015. $300 \mathrm{p}$.

BERGER, Ben. Political theory, political science, and the end of civic engagement. Perspectives on Politics. v. 7, n. 2, p. 335356, june 2009 .

BETHEL, Leslie. Prefácio geral. In: BETHEL, Leslie. A América Latina após 1930: Estado e política. São Paulo: Editora da Universidade de São Paulo, 2009. p. 10-12. v. 7. 
BOBBIO, Norberto; MATTEUCCI, Nicola; PASQUINO, Gianfranco (Org.). Dicionário de política. 8. ed. Brasília: Editora Universidade de Brasília, 1995. v. 2. 1076 p.

O futuro da democracia. 11. ed. São Paulo: Paz e Terra, 2009. 207 p.

BRAMAN, Sandra. The emergent global information policy regime. New York: Palgrave Macmillan, 2004. 262 p.

BRASIL. Controladoria-Geral da União. Acesso à informação pública: uma introdução à Lei $n^{\circ} 12.527$, de 18 de novembro de 2011. Brasília: CGU, 2011. 26 p.

BRAUD, Philippe. La notion de liberté publique en droit français. Paris: Libr. générale de droit et de jurisprudence, 1968. p. 1-6.

BRAY, Daniel; SLAUGHTER, Steven. Global democratic theory: a critical introduction. Cambridge: Polity Press, 2015. 188 p.

CYRANEK, Günther et al. Prólogo. In: MENDEL, Toby. El derecho a la información en América Latina. Quito: UNESCO, 2009. p. 2-3.

COELHO, Simone de Castro Tavares. Terceiro setor: um estudo comparado entre Brasil e Estados Unidos. São Paulo: Senac, 2000. 287 p.

DARNTON, Robert. A questão dos livros: passado, presente e futuro. São Paulo: Companhia das Letras, 2010. 231 p.

DECLARAÇÃO universal dos direitos humanos. 1949. Disponível em:

<http://www.ohchr.org/EN/UDHR/Documents/UDHR Translations/por.pdf>. Acesso em: 9 mar. 2018.

DIAS, Reinaldo. Ciência política. São Paulo: Atlas, 2013. 305 p.

DUPUIS, Georges. Préface. In: BRAUD, Philippe. La notion de liberté publique en droit français. Paris: Libr. générale de droit et de jurisprudence, 1968. p. 1-6.

EQUADOR. Ley $n^{\circ}$ 34, de 2004. Disponível em: <http://www.justicia.gob.ec/wp-content/uploads/2015/05/LEY-ORGANICA-DETRANSPARENCIA-Y-ACCESO-A-LA-INFORMACION-PUBLICA.pdf>. Acesso em: 9 mar. 2018.

ÉROSTEGUI, Susana. Sociedade civil, participação cidadã e democracia no novo contexto político da América Latina. In: SERAFIN, Lizandra; MORONI, José Antônio (Org.). Sociedade Civil e novas institucionalidades democráticas na América Latina: dilemas e perspectivas. São Paulo: Semear, 2009. 286 p.

FONSECA, Maria Odila. Informação e direitos humanos: acesso às informações arquivísticas. Ciência da Informação, 1999 , v. 28, n. 2, p. 146-154. Disponível em: <http://www.scielo.br/scielo. php?script=sci arttext\&pid=S0100$19651999000200007 \&$ lng=en\&nrm=iso>. Acesso em: 9 mar. 2018.

FRANCO, Augusto de. A questão do fim público das organizações do Terceiro Setor. In: RELATÓRIO sobre o desenvolvimento humano no Brasil. São Paulo: PNUD/IPEA, 1997. p. 87-109.

FROHMANN, Bernd. Taking information policy beyond information science: applying the actor network theory. In: ANNUAL CONFERENCE OF THE CANADIAN ASSOCIATION FOR INFORMATION ANNUAL CONFERENCE, v. 23, 1995. Disponível em: <http://citeseerx.ist.psu.edu/viewdoc/download?doi=10.1.1.517.5320\&rep=rep1\&type=pdf>. Acesso em: 9 mar. 2018.

FUENMAYOR ESPINA, Alejandro. El derecho de acceso de los ciudadanos a la información pública: Análisis jurídico y recomendaciones para una propuesta de ley modelo sobre el derecho de acceso de los ciudadanos a la información pública. San José: Unesco, 2004. 107 p.

GONZÁLEZ DE GÓMEZ, Maria Nélida. As relações entre ciência, Estado e sociedade: um domínio de visibilidade para as questões da informação. Ciência da Informação, v. 32, n. 1, p. 60-76, jan./abr. 2003.

GOYARD-FABRE, Simone. O que é democracia? São Paulo: Martins Fontes, 2003. 365 p.

GUIMARÃES, Arianna Stagni. Direito à comunicação: relação entre os meios de comunicação e o exercício da democracia. São Paulo: Lex, 2013. 118 p.

GUROVITZ, Helio. O que piorou no mundo com a internet. Época, n. 1009, p. 62, 23 ou. 2017.

GUTTERIDGE, Haroldo Cooke. Comparative law: an introduction to the comparative method of legal study \& research. 2 nd ed. Cambridge: University Press, 1949. 214 p.

HEINEN, Juliano. Comentários à lei de acesso à informação. Belo Horizonte: Fórum, 2014. 310 p.

HIGINO, Anderson Fabian Ferreira; ARAÚJO, Ronaldo Ferreira de; SCOTT, Carolina de Souza Paes. Construção de políticas de informação: aspectos epistemológicos e metodológicos. Liinc em revista, v. 4, n. 2, p. 281-297, set. 2008.

HIGOUNET, Charles. História concisa da escrita. São Paulo: Parábola Editorial, 2003. 187 p. 
KHAN, Abdul Waheed. Introdução. In: MENDEL, Toby. Liberdade de informação um estudo comparado. Brasília: UNESCO, 2009. $172 \mathrm{p}$.

MELO, José Marques de; SATHLER, Luciano (Org.). Direitos à comunicação na sociedade da informação. São Bernardo do Campo: UMESP, 2005. 288 p.

MENDEL, Toby. Liberdade de informação um estudo comparado. Brasília: UNESCO, 2009. 172 p.

MIRANDA, Pontes. Democracia, liberdade, igualdade: os três caminhos. São Paulo: Saraiva, 1979. 465 p.

MONTESQUIEU. O espírito das leis: as formas de governo, a federação, a divisão dos poderes. 9. ed. São Paulo: Saraiva, 2010. $231 \mathrm{p}$.

PASQUALI, Antonio. Um breve glossário descritivo sobre a comunicação e informação. In: MELO, José Marques de; SATHLER, Luciano (Org.). Direitos à comunicação na sociedade da informação. São Bernardo do Campo: UMESP, 2005. p. $15-48$.

PERONDI, Regina Heurich. Partidos políticos e Terceiro Setor. Brasília: Fundação Ulysses Guimarães, 2007. 185 p.

PINHEIRO, Marta Macedo Kerr. O processo de construção de políticas de informação. In: MOURA, Maria Aparecida. A construção social do acesso à informação no Brasil: contexto, historicidade e repercussões. Belo Horizonte: Ed. UFMG, 2014. p. $27-46$

PINTO, Wagner de Souza. Análise das práticas administrativas de uma fundação empresarial aberta. 2001. Dissertação (Mestrado executivo em Administração) - Escola Brasileira de Administração Pública, Rio de Janeiro, Fundação Getúlio Vargas.

PIRES JÚNIOR, José Fernandes. O sofrimento dos filósofos. São Paulo: Biblioteca 24 horas, 2014. 128 p.

REGULES, Luis Eduardo Patrone. Terceiro Setor: regime jurídico das OSCIPs. São Paulo: Método, 2006. 223 p.

ROTHBERG, Danile; NAPOLITANO, Carlo José, RESENDE, Letícia Passos. Estado e burocracia: limites de aplicação da lei deacesso à informação no Brasi. Fronteiras, v. 15, n. 2, p. 108-117, maio/ago. 2013.

SALAMON, Lester. A emergência do Terceiro Setor: uma revolução associativa global. Revista de Administração, v. 33, n. 1 , p. 5-11, jan./mar. 1998.

SARLET, Ingo Wolfgang; MONTILLA MARTOS, José Antonio. O direito à informação na ordem constitucional brasileira: breves apontamentos; In: Advogado, 2016. p. 11-26 . Acesso à informação como direito fundamental e dever estatal. Porto Alegre: Livr. do

SHERA, Jesse. Epistemologia social, semântica e Biblioteconomia. Ciência da Informação, v. 6, n. 1, p. 9-12, 1977. Disponível em: <http://revista.ibict.br/ciinf/article/view/92/92>. Acesso em: 9 mar. 2018.

SILVA, José Afonso da. O sistema representativo, democracia semidireta e democracia participativa. Revista do Advogado, v. 23, n. 73, p. 94-108, nov. 2003

SILVA, Shirlene Linny. Transição política e a construção do direito de acesso aos arquivos da/sobre a repressão. In: MOURA, Maria Aparecida. A construção social do acesso à informação no Brasil: contexto, historicidade e repercussões. Belo Horizonte: Ed. UFMG, 2014. p. 85-106.

SILVA, Terezinha Elisabeth da et. al. Acesso à informação: ações e estratégias da Câmara dos Deputados para atender à Lei 12.527/2011. 2012. Disponível em: <http://www2.camara.leg.br/a-camara/cursos/posgraduacao/grupo-de-pesquisa-eextensao-gpe/projetos/Projeto GPE 06.12 Terezinha Acesso Informaosemdadospessoais.pdf>. Acesso em: 9 mar. 2018.

SORJ, Bernardo. (Des)Construindo a sociedade civil na América Latina (p. 7-16). In: SORJ, Bernardo (Org.). Usos, abusos e desafios da sociedade civil na América Latina. São Paulo: Paz e Terra, 2010. p. 7-16.

TOCQUEVILLE, Alexis de. A democracia na América. São Paulo: Folha de São Paulo, 2010. 324 p.

VILLANUEVA, Ernesto. Derecho de la información. Cidade do México: Câmara de Diputados, 2006. 398 p. 


\section{Dados dos autores}

Thiago Gomes Eirão

Doutorando em Ciência da Informação pela Universidade de Brasília. Mestre em Ciência da Informação pela Universidade de Brasília. Analista Legislativo da Câmara dos Deputados.

thiagoe@gmail.com

\section{Fernando César Lima Leite}

Doutor em Ciência da Informação pela Universidade de Brasília. Professor adjunto da Faculdade de Ciência da Informação (FCl/UnB) e diretor da Biblioteca Central da Universidade de Brasília. fernandodfc@gmail.com

Recebido - Received: 2017-08-08

Aceitado - Accepted: 2018-03-08

\section{$(\mathrm{cc}) \mathrm{BY}^{\mathrm{B}}$}

This work is licensed under a Creative Commons Attribution 4.0

United States License.

\section{ULIS DDofe}

This journal is published by the University Library System of the University of Pittsburgh as part of its D-Scribe Digital Publishing Program and is cosponsored by the University of Pittsburgh Press. 